\title{
Osteodiscus abyssicola, a new snailfish (Cottoidei: Liparidae) collected off the Pacific coast of northern Japan
}

\author{
KENTA MURASAKI ${ }^{*}$, YOSHIAKI KAI ${ }^{2}$, HIROMITSU ENDO ${ }^{3} \&$ ATSUSHI FUKUI ${ }^{4}$ \\ ${ }^{1}$ Institute of Oceanic Research and Development, Tokai University, 3-20-1 Orido, Shimizu-ku, Shizuoka 424-8610, Japan \\ ${ }^{2}$ Maizuru Fisheries Research Station, Field Science Education and Research Center, Kyoto University, Nagahama, Maizuru, Kyoto \\ 625-0086, Japan. ڤ"kai.yoshiaki.4c@kyoto-u.ac.jp; @ https://orcid.org/0000-0002-0991-5173 \\ ${ }^{3}$ Laboratory of Marine Biology, Faculty of Science and Technology, Kochi University, 2-5-1 Akebono-cho, Kochi 780-8520, Japan \\ "=endoh@kochi-u.ac.jp; (1) https://orcid.org/0000-0001-6916-6322 \\ ${ }^{4}$ School of Marine Science and Technology, Tokai University, 3-20-1 Orido, Shimizu-ku, Shizuoka 424-8610, Japan

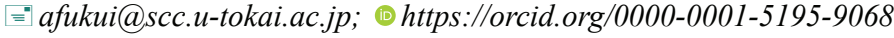 \\ *Corresponding author. $="$ murasaki-619@hope.tokai-u.jp; @ https://orcid.org/0000-0002-3433-5795
}

\begin{abstract}
The snailfish Osteodiscus abyssicola sp. nov. is described from a single specimen collected off the Pacific coast of Hokkaido, northern Japan, at a depth of 4,671-4,744 m. It is distinguished from all currently recognized congeners by the following combination of characters: vertebrae 49; dorsal-fin rays 44; anal-fin rays 39; principal caudal-fin rays 8; pyloric caeca 5; mouth horizontal; teeth on both jaws simple and sharp, without cusps; upper and lower jaw symphyses without diastema; cephalic pore sizes moderate, similar to or slightly larger than nostril; gill slit extending ventrally to $2^{\text {nd }}$ pectoral-fin ray base; pectoral fin notched; mandibular symphysis to center of anus $101.6 \%$ head length (HL); posterior edge of pelvic disk to center of anus $15.5 \% \mathrm{HL}$; epural 1, reduced; epipleural ribs absent. An emended diagnosis and key to the species of Osteodiscus are provided.
\end{abstract}

Key words: Actinopterygii, new species, Osteodiscus cascadiae, Osteodiscus andriashevi, Osteodiscus rhepostomias

\section{Introduction}

Snailfishes in the family Liparidae (Scorpaeniformes: Cottoidei) are a morphologically diverse group of marine fishes, currently comprising about 32 genera with over 430 species worldwide (Chernova et al. 2004; Orr et al. 2019), with new species still being frequently described (e.g., Stein 2012; Orr 2016; Murasaki et al. 2019; Chernova et al. 2020; Kai et al. 2020). Occupying an unusually wide vertical habitat range, they are known from tidal pools to over 8,000 m depth (Chernova et al. 2004; Gerringer et al. 2017). Members of Liparidae can be recognized by the following morphological characters: body tadpole-like in shape, caudal region elongate; skin soft, including a thick or thin subdermal gelatinous layer; scales absent, but small prickles in some species; cephalic pore system well developed, but lacking a complete lateral line and pores; third infraorbital needle-like, posterior tip almost reaching to preopercle; only third pharyngobranchial present; dorsal and anal fins single, frequently connected to caudal fin by membrane; caudal-fin rays unbranched; pelvic fins modified into a variously shaped disk or completely lost (Kido 1988; Chernova et al. 2004; Smith \& Busby 2014; Nelson et al. 2016). While many genera have been proposed, their phylogenetic relationships are so far largely uncertain (see Kido 1988; Orr et al. 2019).

The deep-sea snailfish group Osteodiscus Stein, 1978, is primarily distinguished from other genera by its unique pelvic disk skeleton (Stein 1978, 2012; Pitruk \& Fedorov 1990; Murasaki et al. 2021) and currently comprises three species: Osteodiscus andriashevi Pitruk \& Fedorov, 1990; Osteodiscus cascadiae Stein, 1978; Osteodiscus rhepostomias Stein, 2012. During our ongoing taxonomic study of Japanese snailfishes, we discovered a single specimen of Osteodiscus collected from the abyssal zone off the Pacific coast of Hokkaido, neighboring the most southern part of the Kuril-Kamchatka Trench. Because the specimen clearly differed from all currently recognized congeners, it is described herein as a new species, and an emended diagnosis and key to the species of Osteodiscus are provided. 
The specimen was collected by a small Sigsby-Agassiz type beam trawl ( $2 \mathrm{~m}$ span), and preserved in $70 \%$ ethanol. Counts, measurements, and descriptive terminology followed Andriashev \& Stein (1998), with the exceptions of cephalic pore terminology, which follows Stein et al. (2001), and osteological terminology of the pelvic girdle, which follows Kido (1988). Vertebral and median-fin ray counts were made from radiographs. Cephalic pores were examined after staining with Aniline Blue (Wako Chemicals). Colors of the peritoneum, stomach, and pyloric caeca were noted following abdominal dissection. However, dissection and staining of the holotype for observation of the pectoral girdle were not attempted due to the possibility of resulting damage. Standard length and head length are abbreviated as SL and HL, respectively. Specimens examined in this study are deposited in the National Museum of Nature and Science, Japan (NSMT) and Zoological Institute of the Russian Academy of Sciences, Russia (ZIN).

\section{Osteodiscus Stein, 1978}

Standard Japanese name: Hariban-kusauo-zoku

Osteodiscus Stein, 1978: 24 (original designation, type species Osteodiscus cascadiae Stein, 1978 by monotypy).

Diagnosis. Osteodiscus is distinguished from all other genera by the following combination of characters: nostril single on each side; cephalic pore sizes ranging in size from similar to and much larger than nostril; branchiostegal rays six; pelvic disk present, skeletal, fleshly margin absent, basipterygia and pelvic rays covered only by thin skin, pelvic rays webbed between tips, webbing attenuated posteriorly; pleural ribs absent.

Species included. Four species: Osteodiscus abyssicola sp. nov.; Osteodiscus andriashevi Pitruk \& Fedorov, 1990; Osteodiscus cascadiae Stein, 1978; Osteodiscus rhepostomias Stein, 2012.

Distribution. All known species are from the Pacific Ocean: $O$. abyssicola sp. nov. from the western North Pacific, off the Pacific coast of northern Japan, in 4,671-4,744 m depth; $O$. andriashevi from the western North Pacific, southern Sea of Okhotsk and off the Pacific coast of northern Japan, in 1,745-2,108 m depth; O. cascadiae from the eastern North Pacific, off southern British Columbia to central California, in 2,195-3,500 m depth; $O$. rhepostomias from the western South Pacific, off southeastern New Zealand, in 2,786-2,821 m depth (Stein 1978, 2012; Pitruk \& Fedorov 1990; Stein et al. 2006; Murasaki et al. 2021; this study).

Comments. Osteodiscus was diagnosed in part by a deeply notched pectoral fin (Stein 1978, 2012). However, this character is removed from the emended diagnosis of the genus because $O$. andriashevi has an unnotched pectoral fin (see Pitruk \& Fedorov 1990; Murasaki et al. 2021). Kido (1988) proposed three autapomorphies of Osteodiscus (proximal pectoral radials two; second and third pelvic rays widely spaced; epipleural ribs absent), based on his morphological phylogenetic analysis. However, $O$. andriashevi, described two years later, has three or four proximal pectoral radials, and epipleural ribs (Pitruk \& Fedorov 1990; Murasaki et al. 2021). While O. rhepostomias has two proximal pectoral radials, the first radial is oddly shaped (an inverted triangle) and unusually large compared to other snailfishes (Stein 2012). Additionally, it appears that the second and third pelvic rays of $O$. rhepostomias are not widely spaced (see Stein 2012: fig. 16). Accordingly, the three characters proposed by Kido (1988) have also been deleted from the generic diagnosis.

Although species of Osteodiscus can be clearly diagnosed from all other snailfishes by the emended diagnosis given above, the phylogenetic position of the genus is essentially unknown and its monophyly unproven. Kido (1988) placed Osteodiscus in a basal position to Careproctus Krøyer, 1862 and Paraliparis Collett, 1879, but his analysis included only a single species of the former, $O$. cascadiae. In a recent molecular phylogenetic study by Orr et al. (2019), although Osteodiscus recovered a monophyletic group with species of Careproctus from the Southern Ocean, the authors conservatively proposed the informal name "Osteocareprocta" for the monophyletic group, since their analysis was also based only on $O$. cascadiae. Subsequently, Careproctus laperousei Chernova, Thiel \& Eidus, 2020, characterized by reduced musculature on the pelvic disk (similar to the condition in species of Osteodiscus), was described from a single specimen collected from the northern slope of the Kuril-Kamchatka Trench, western North Pacific. However, C. laperousei clearly differed from species of Osteodiscus in having a fleshly margin on the pelvic disk and two paired pleural ribs on each posterior abdominal vertebra (Stein 1978, 2012; Kido 1988; Pitruk \& Fedorov 1990; Chernova et al. 2020; Murasaki et al. 2021; this study). Apart from O. cascadiae, specimens of 
Osteodiscus are very rare, being known only from the types or very limited additional specimens, and no genetic data are available. Clarification of the phylogenetic position and monophyly of Osteodiscus is dependent upon the collection of additional specimens, including those of C. laperousei.

\section{Key to species of Osteodiscus}

1a. Mouth distinctly oblique, principal caudal-fin rays $9 \ldots \ldots \ldots \ldots \ldots \ldots \ldots \ldots \ldots \ldots \ldots$. rhepostomias

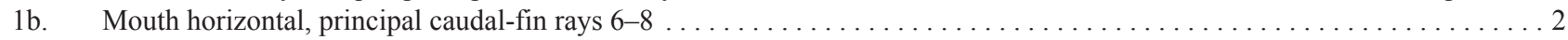

2a. Pectoral fin unnotched, teeth blunt, anal-fin rays $46-49 \ldots \ldots \ldots \ldots \ldots \ldots \ldots \ldots \ldots \ldots \ldots \ldots \ldots \ldots \ldots \ldots$ andriashevi

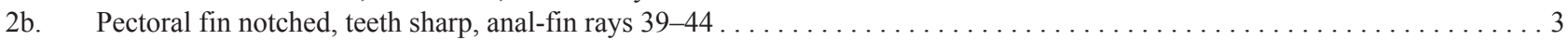

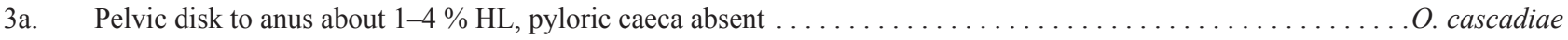

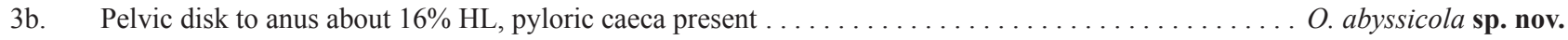

\section{Osteodiscus abyssicola sp. nov.}

New Japanese name: Tsugomori-hariban-kusauo

Figs. 1, 2; Table 1

urn:lsid:zoobank.org:act: D12C0636-D7A4-463A-A173-92E234C1D6E5

Holotype. NSMT-P 109986, $94.7 \mathrm{~mm}$ SL, immature female, south-southwest of Kushiro, Hokkaido, northern Japan; $41^{\circ} 43.46^{\prime} \mathrm{N}, 144^{\circ} 53.63^{\prime} \mathrm{E}-41^{\circ} 42.24^{\prime} \mathrm{N}, 144^{\circ} 52.12^{\prime} \mathrm{E} ; 4,671-4,744 \mathrm{~m}$ depth, 4 Aug. 1992, R/V Hakuho-maru.

Diagnosis. A species of Osteodiscus distinguished from all currently recognized congeners by the following combination of characters: vertebrae 49; dorsal-fin rays 44 ; anal-fin rays 39 ; principal caudal-fin rays 8 ; pyloric caeca 5; mouth horizontal; teeth on both jaws simple and sharp, without cusps; upper and lower jaw symphyses without diastema; cephalic pore sizes moderate, similar to or slightly larger than nostril; gill slit extending ventrally to $2^{\text {nd }}$ pectoral-fin ray base; pectoral fin notched; mandibular symphysis to center of anus $101.6 \% \mathrm{HL}$; posterior edge of pelvic disk to center of anus $15.5 \% \mathrm{HL}$; epural 1, reduced; epipleural ribs absent.

Description. Counts and measurements given in Table 1. Body slender, anteriorly oval in cross section, tapering gradually and becoming strongly compressed posteriorly, deepest at nape (= vertical depth through center of pelvic disk) (Fig. 1A, B). Skin thin, fragile (partly damaged); thin subdermal gelatinous layer present; prickles apparently absent. Head large, dorsal profile rounded from nape to snout. Snout blunt and deep, slightly projecting. Mouth subterminal, horizontal when closed, oral cleft extending to below center of orbit; outer margin of premaxilla completely covered by upper lip; posterior margin of maxilla slightly beyond to vertically below posterior margin of orbit. Lower jaw slightly inferior, anterior part of premaxillary tooth plates visible from ventral aspect of head; posterior half of outer margin of mandible covered by lower lip, anterior tip of lip slightly angled ventrally. Teeth on both jaws simple, sharp, without cusps, in about 20 oblique rows of 5-9 teeth forming bands, inner teeth larger than outer teeth (Fig. 2A). Upper and lower jaw symphyses without diastema. Single nostril tube-like, horizontally level with center of orbit. Eye and orbit small, dorsal contour of orbit below dorsal profile of head; pupil round. Cephalic pore sizes moderate, similar to or slightly larger than nostril: nasal pores 2, maxillary pores 6? [6th (= supraorbital) pore apparently present as shown in Fig. 1A, but difficult to discern due to poor skin condition], preoperculo-mandibular pores 7, suprabranchial pore 1; pore pattern 2-6?-7-1. Coronal pore absent. Chin pores (= anteriormost preoperculo-mandibular pores) paired, opening directly on skin surface, well separated from each other. Free neuromasts not apparent in damaged skin. Gill slit relatively short, upper margin horizontally level with lower margin of orbit, lower margin extending ventrally to $2^{\text {nd }}$ pectoral-fin ray base. Opercular flap angular, pointing posteroventrally, supported by two spines: upper spine (from opercle) and lower spine (from subopercle) extending posterior to vertical through dorsal-fin origin.

Dorsal- and anal-fin rays not buried in gelatinous layer. Anteriormost and $2^{\text {nd }}$ pterygiophores of dorsal fin without rays, inserted between $3^{\text {rd }}$ and $4^{\text {th }}$, and $4^{\text {th }}$ and $5^{\text {th }}$ neural spines, respectively. Anal-fin origin below $8^{\text {th }}$ dorsal-fin ray base. Hypural plates fused with terminal vertebral centrum, upper and lower plates separated by a narrow slit. Single reduced epural present. Pleural ribs and epipleural ribs absent.

Pectoral fin moderately or deeply notched (condition unclear due to damage to some rays in notch and lower lobe, as shown in Fig. 1A). Upper lobe rays slightly protruding from membrane at tip; $2^{\text {nd }}$ and $3^{\text {rd }}$ uppermost rays 
longest, reaching to $4^{\text {th }}$ anal-fin ray base. Notch and lower lobe rays filamentous, nearly completely free from membrane. Uppermost pectoral-fin base just below level of posterior margin of maxilla; lowermost pectoral-fin base below anterior margin of orbit.

TABLE 1 Counts and measurements of Osteodiscus abyssicola sp. nov., holotype, NSMT-P 109986

\begin{tabular}{|c|c|c|c|}
\hline \multirow[t]{3}{*}{ Character } & \multirow[t]{3}{*}{ Counts } & \multicolumn{2}{|c|}{ In $\%$ of measurements } \\
\hline & & Standard length & Head length \\
\hline & & $94.7 \mathrm{~mm}$ & $24.5 \mathrm{~mm}$ \\
\hline Vertebrae (abdominal + caudal) & $49(10+39)$ & & \\
\hline Dorsal-fin rays & 44 & & \\
\hline Anal-fin rays & 39 & & \\
\hline Pectoral-fin rays & 21 & & \\
\hline Caudal-fin rays & 9 & & \\
\hline Principal caudal-fin rays (upper + lower) & $8(4+4)$ & & \\
\hline Procurrent caudal-fin rays (upper + lower) & $1(1+0)$ & & \\
\hline Branchiostegal rays & 6 & & \\
\hline Pyloric caeca & 5 & & \\
\hline Head length & & 25.9 & \\
\hline Head width & & 15.2 & 58.8 \\
\hline Maximum body depth & & 22.6 & 87.3 \\
\hline Body depth at anal-fin origin & & 14.3 & 55.1 \\
\hline Snout length & & 10.0 & 38.8 \\
\hline Maxilla length & & 13.5 & 52.2 \\
\hline Mandible length & & 13.4 & 51.8 \\
\hline Mouth width & & 13.6 & 52.7 \\
\hline Orbit length & & 4.0 & 15.5 \\
\hline Eye diameter & & 4.0 & 15.5 \\
\hline Interorbital width & & 10.8 & 41.6 \\
\hline Bony interorbital width & & 4.4 & 17.1 \\
\hline Suborbital depth to maxilla & & 5.4 & 20.8 \\
\hline Gill slit length & & 9.6 & 37.1 \\
\hline Pectoral-fin ray length in upper lobe & & 20.9 & 80.8 \\
\hline Pectoral-fin ray length in lower lobe & & - & - \\
\hline Pectoral-fin ray length at notch & & - & - \\
\hline Pelvic disk length & & 11.6 & 44.9 \\
\hline Pelvic disk width & & 9.6 & 37.1 \\
\hline Caudal fin length & & - & - \\
\hline Predorsal fin length & & 27.5 & 106.1 \\
\hline Snout to anterior edge of pelvic disk & & 12.9 & 49.8 \\
\hline Mandibular symphysis to anterior edge of pelvic disk & & 11.5 & 44.5 \\
\hline Snout to center of anus & & 27.7 & 106.9 \\
\hline Mandibular symphysis to center of anus & & 26.3 & 101.6 \\
\hline Posterior edge of pelvic disk to center of anus & & 4.0 & 15.5 \\
\hline Preanal fin length & & 36.7 & 142.0 \\
\hline Center of anus to anal-fin origin & & 10.9 & 42.0 \\
\hline Dorsal-fin origin to anal-fin origin & & 23.0 & 89.0 \\
\hline
\end{tabular}


Pelvic disk large, longer than wide, moderately upturned at posterior part; skeletal, musculature greatly reduced, fleshly margin absent (Fig. 2B). Basipterygia and six paired pelvic rays (anteriormost spine, posterior five soft rays) covered only by thin skin, internal structures visible through skin. Bases of anteriormost and $2^{\text {nd }}$ pelvic rays more widely spaced than bases of other rays; anteriormost ray supported by subpelvic process (= part of anterior half of basipterygium), posterior five rays supported by posterior half of basipterygium. Pelvic rays webbed between tips; webs somewhat attenuated posteriorly on disk. Anus well separated from posterior edge of pelvic disk, vertically below dorsal-fin origin. Minute genital papilla-like process at posterior of anus. Stomach and short pyloric caeca located on left side of visceral cavity.
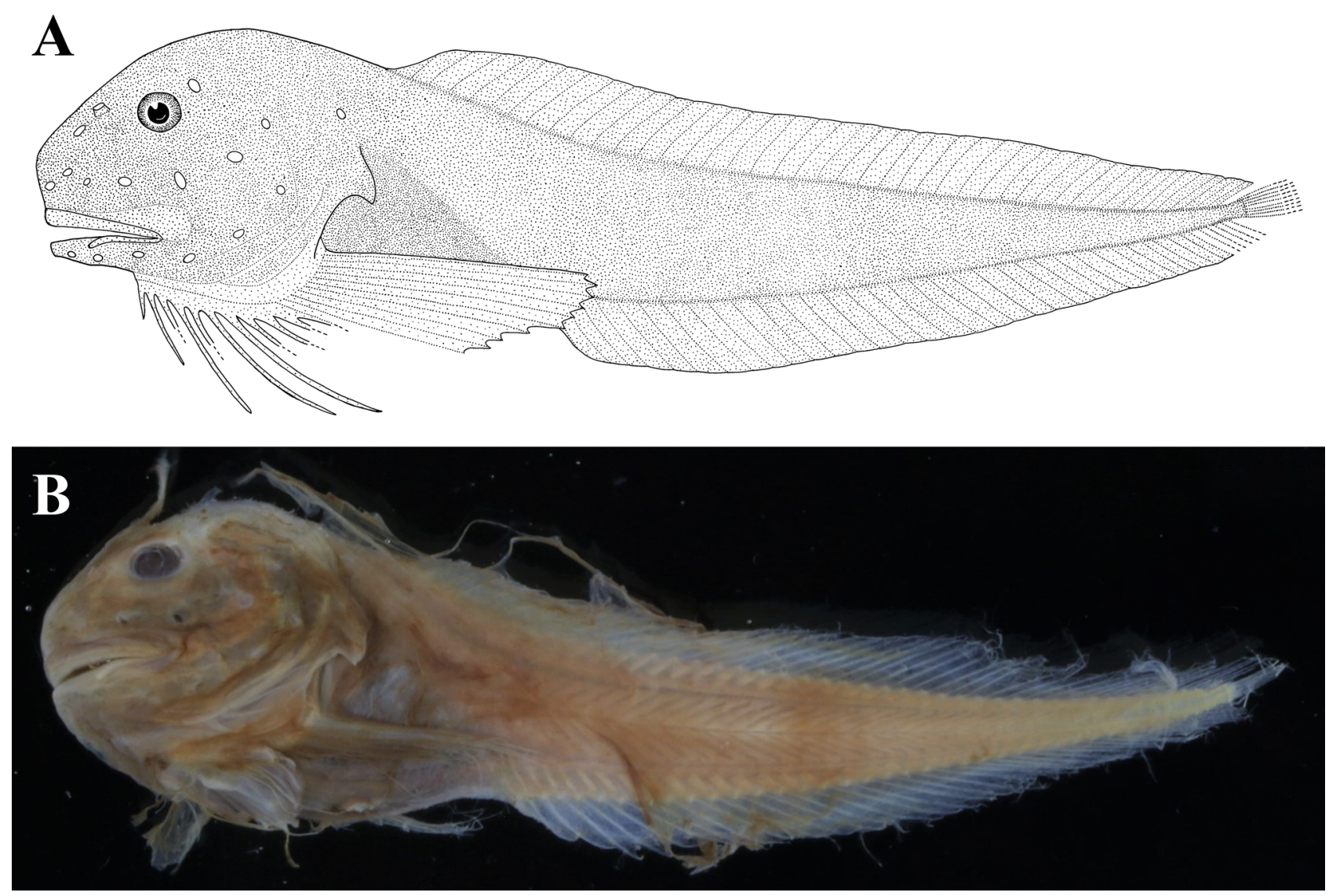

FIGURE 1. Osteodiscus abyssicola sp. nov., holotype, NSMT-P 109986, 94.7 mm SL. (A) drawing; (B) photograph of preserved specimen.

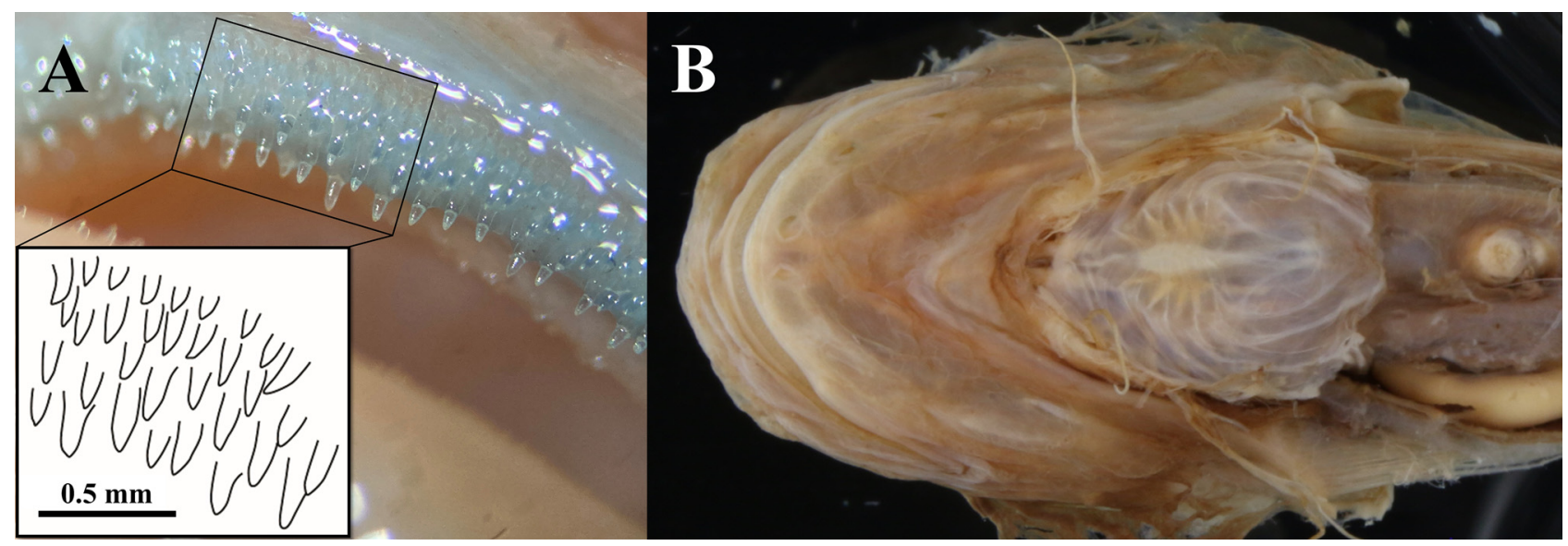

FIGURE 2. Teeth on right side of premaxilla (A) and ventral view of head and abdominal region (B) of Osteodiscus abyssicola sp. nov., holotype, NSMT-P 109986, 94.7 mm SL. 
Color in alcohol. Body and fins brown, head somewhat darker (Fig. 1B). Eye and peritoneum black. Gill cavity dark brown. Stomach, pyloric caeca, and genital papilla-like process pale.

Distribution. Western North Pacific, south-southwest of Kushiro, Hokkaido, northern Japan, at a depth of 4,671-4,744 m.

Etymology. The specific name "abyssicola", a noun in apposition, is derived from Latin "abyssus" (abyss) and "cola" (dweller), referring to the deeper habitat of this species compared to congeners. The Japanese name "Tsugomori" is an archaic term in Japanese, modified from "tsuki-gomori" (hiding moon), and refers to a dark night.

Comparisons. Osteodiscus abyssicola sp. nov. shares a horizontal mouth with two congeners, O. cascadiae and O. andriashevi (Stein 1978; Pitruk \& Fedorov 1990; Murasaki et al. 2021; this study). However, O. abyssicola sp. nov. clearly differs from $O$. cascadiae in having 8 principal caudal-fin rays (vs. 6-7), 5 pyloric caeca (vs. 0 ), the anus well separated from the pelvic disk posterior edge $(15.5 \% \mathrm{HL}$ vs. immediately posterior to or slightly further from disk, 1-4\% HL), moderate-sized cephalic pores, similar to or slightly larger than nostril (vs. notably larger than nostril), absence of diastemata at both jaw symphyses (vs. present), and presence of a reduced epural (vs. absent) (Stein 1978, 2012; Kido 1988; this study). It also differs from $O$. andriashevi in having 49 vertebrae (vs. 55-60), 44 dorsal-fin rays (vs. 52-54), 39 anal-fin rays (vs. 46-49), 8 principal caudal-fin rays (vs. 7), sharp teeth without cusps (vs. blunt, some with lateral cusps), a notched pectoral fin (vs. unnotched), and the absence of epipleural ribs (vs. present) (Pitruk \& Fedorov 1990; Murasaki et al. 2021; this study). Additionally, the space between the $1^{\text {st }}$ and $2^{\text {nd }}$ pelvic-fin ray bases is greater than between the other fin ray bases in $O$. abyssicola sp. nov. (vs. space between $2^{\text {nd }}$ and $3^{\text {rd }}$ ray bases greater than between others in O. cascadiae and O. andriashevi) (Stein 1978; Kido 1988; Pitruk \& Fedorov 1990; this study). The remaining species, O. rhepostomias, has a distinctly oblique mouth (vs. horizontal in O. abyssicola sp. nov.), 9 principal caudal-fin rays (vs. 8), a shorter distance from mandible to anus, $68.2 \% \mathrm{HL}$ (vs. $101.6 \% \mathrm{HL}$ ), a clear diastema at the lower jaw symphysis (vs. absent), and a large gill slit, extending ventrally to about $9^{\text {th }}$ pectoral-fin ray base (vs. small, extending to $2^{\text {nd }}$ pectoral-fin ray base) (Stein 2012; this study).

\section{Comparative material}

Osteodiscus andriashevi: paratype, ZIN 49565, one of two specimens with the same registration number, photographs and radiographs only, $165 \mathrm{~mm} \mathrm{SL}$, female, Sea of Okhotsk, $48^{\circ} 07^{\prime} \mathrm{N}, 146^{\circ} 59^{\prime} \mathrm{E}, 1,766-1,745 \mathrm{~m}$ depth, 22 May 1989, Freezer fishing trawler Darwin (trawl 38), otter trawl; NSMT-P 97212, $150.3 \mathrm{~mm}$ SL, female, off Iwate, Japan, $38^{\circ} 39.9^{\prime} \mathrm{N}, 143^{\circ} 7.5^{\prime} \mathrm{E}-38^{\circ} 38.4^{\prime} \mathrm{N}, 143^{\circ} 8.9^{\prime} \mathrm{E}, 1,997-2,108 \mathrm{~m}$ depth, 31 May 1989, R/V Tansei-maru (KT-89-07, SR103), beam trawl.

\section{Acknowledgments}

We are grateful to G. Shinohara and M. Nakae (NSMT) for access to the collections of the museum, and N. V. Chernova (ZIN) for providing photographs and radiographs of the paratype of Osteodiscus andriashevi, and acknowledge the roles of the captain and crew of R/V Hakuho-maru in collecting the holotype of the new species. G. S. Hardy (Ngunguru, New Zealand) reviewed the manuscript, and members of the Laboratory of Marine Biology, Faculty of Science and Technology, Kochi University (BSKU) assisted in taking radiographs of the holotype of the new species. This study was supported in part by Grants-in-Aid for the Promotion of Scientific Research (C) (no. 18K05792) from the Ministry of Education, Culture, Sports, Science and Technology, Japan to the last author.

\section{References}

Andriashev, A.P. \& Stein, D.L. (1998) Review of the snailfish genus Careproctus (Liparidae, Scorpaeniformes) in Antarctic and adjacent waters. Contributions in Science, Los Angeles, 470, 1-63.

Chernova, N.V., Stein, D.L. \& Andriashev, A.P. (2004) Family Liparidae Scopoli 1777—snailfishes. California Academy of Sciences Annotated Checklists of Fishes, 31, 1-72.

Chernova, N., Thiel, R. \& Eidus, I. (2020) Four new species of Careproctus (Cottoidei: Liparidae) from the deep-water vicinity of the southern Kuril Islands (Western North Pacific). Zootaxa, 4821 (1), 71-87. 
https://doi.org/10.11646/zootaxa.4821.1.3

Collett, R. (1879) Fiske fra Nordhavs-Expeditionens sidste Togt, Sommeren 1878. Forhandlinger I Videnskabs-Selskabet $i$ Christiania, 14, 1-106. [for 1878]

Gerringer, M.E., Linley, T.D., Jamieson, A.J., Goetze, E. \& Drazen, J.C. (2017) Pseudoliparis swirei sp. nov.: a newly-discovered hadal snailfish (Scorpaeniformes: Liparidae) from the Mariana Trench. Zootaxa, 4358 (1), 161-177. https://doi.org/10.11646/zootaxa.4358.1.7

Kai, Y., Murasaki, K., Misawa, R., Fukui, A., Morikawa, E. \& Narimatsu, Y. (2020) A new species of snailfish of the genus Paraliparis (Liparidae) from the western North Pacific, with a redescription of the poorly known species Paraliparis mandibularis. ZooKeys, 968, 143-159.

https://doi.org/10.3897/zookeys.968.56057

Kido, K. (1988) Phylogeny of the family Liparididae, with the taxonomy of the species found around Japan. Memoirs of the Faculty of Fisheries, Hokkaido University, 35, 125-256.

Krøyer, H.N. (1862) Nogle Bidrag til Nordisk ichthyologi. Naturhistorisk Tidsskrift, Kjøbenhavn, Series 3, 1, $233-310$.

Murasaki, K., Kai, Y., Endo, H. \& Fukui, A. (2021) First Japanese record of the snailfish Osteodiscus andriashevi (Liparidae), collected off Iwate, Japan. Japanese Journal of Ichthyology. [10 May 2021, online first, in Japanese] https://doi.org/10.11369/jji.20-044

Murasaki, K., Takami, M. \& Fukui, A. (2019) Paraliparis variabilidens, a new snailfish (Liparidae) from the Suruga Trough, Japan. Ichthyological Research, 66, 509-514. https://doi.org/10.1007/s10228-019-00692-y

Nelson, J.S., Grande, T.C. \& Wilson, M.V.H. (2016) Fishes of the world. $5^{\text {th }}$ Edition. John Wiley and Sons, Hoboken, New Jersey, xli $+707 \mathrm{pp}$.

Orr, J.W. (2016) Two new species of snailfishes of the genus Careproctus (Liparidae) from the Aleutian Islands, Alaska. Copeia, $104,890-896$. https://doi.org/10.1643/CI-15-378

Orr, J.W., Spies, I., Stevenson, D.E., Longo, G.C., Kai, Y., Ghods, S. \& Hollowed, M. (2019) Molecular phylogenetics of snailfishes (Liparidae: Cottoidei) based on mtDNA and RADseq genomic analyses, with comments on selected morphological characters. Zootaxa, 4642 (1), 1-79. https://doi.org/10.11646/zootaxa.4642.1.1

Pitruk, D.L. \& Fedorov, V.V. (1990) A new species of the genus Osteodiscus Stein (Liparididae) from the Sea of Okhotsk. Voprosy Ikhtiologii, 30 (5), 856-860. [in Russian, English translation in Journal of Ichthyology, 30 (8), 112-118]

Smith, W.L. \& Busby, M.S. (2014) Phylogeny and taxonomy of sculpins, sandfishes, and snailfishes (Perciformes: Cottoidei) with comments of the phylogenetic significance of their early-life-history specializations. Molecular Phylogenetics and Evolution, 79, 332-352. https://doi.org/10.1016/j.ympev.2014.06.028

Stein, D.L. (1978) A review of the deepwater Liparidae (Pisces) from the coast of Oregon and adjacent waters. Occasional Papers of the California Academy of Sciences, 127, 1-55.

Stein, D.L. (2012) A review of the snailfishes (Liparidae, Scorpaeniformes) of New Zealand, including descriptions of a new genus and sixteen new species. Zootaxa, 3588 (1), 1-54. https://doi.org/10.11646/zootaxa.3588.1.1

Stein, D.L., Chernova, N.V. \& Andriashev, A.P. (2001) Snailfishes (Pisces: Liparidae) of Australia, including descriptions of thirty new species. Records of the Australian Museum, 53, 341-406. https://doi.org/10.3853/j.0067-1975.53.2001.1351

Stein, D.L., Drazen, J.C., Schlining, K.L., Barry, J.P. \& Kuhnz, L. (2006) Snailfishes of the central California coast: video, photographic and morphological observations. Journal of Fish Biology, 69, 970-986. https://doi.org/10.1111/j.1095-8649.2006.01167.x 